Effects of experimental and commercial ceramic primers in lithium disilicate surface treatment

Efeitos da aplicação de primers cerâmicos experimentais e comerciais no tratamento superficial do dissilicato de lítio

Dissertação constituída por artigo apresentada à Faculdade de Odontologia de Bauru da Universidade de São Paulo para obtenção do título de Mestre em Ciências no Programa de Ciências Odontológicas Aplicadas, na área de concentração Dentística.

Orientador: Prof. Dr. Paulo Afonso Silveira Francisconi

BAURU

2021 


\section{ABSTRACT \\ Effects of experimental and commercial ceramic primers in lithium disilicate surface treatment}

Universal primers and adhesives, containing silane and MDP, facilitate clinical practice. However, several authors raised questions about this class of materials. Thus, the objective of this research was to evaluate different strategies of silane and MDP application, to elucidate the specific role of these molecules, when used together, in promoting microshear bond strength ( $\mu$ SBS), highlighting mechanisms that could interfere in universal ceramic primers performance, in glass ceramics. For this purpose, 112 Lithium disilicate (IPS e-max CAD) slices were divided into 7 groups, according to surface treatment: conventional silane (SI group), as control; three groups received an experimental primer with $15 \mathrm{wt}$ \% MDP, applied in different ways: alone (PMDP), before silanization (PMDP+SI), and after silane application (SI+PMDP); one group was treated with a "primer-mixed" (PMIX), containing equal proportions of the commercial silane and the solution of $15 \mathrm{wt} . \%$ MDP; two groups received commercial products: Single Bond Universal (SBU) and Clearfil Ceramic Primer (CCP). The best results were obtained for the SI control group. Regarding the silane and MDP application mode, the best results were obtained for SI + PMDP and for the commercial products CCP and SBU. The application steps: PMDP + SI, only PMDP, and PMIX, did not obtain favorable results. Thus, it was possible to conclude that the sequence and the application protocol of silane and MDP influence the bond strength; the intermolecular interaction between silane and MDP, when in the same solution, interferes in the bond strength, but the balance in the concentration of both bifunctional binding agents, can prevent damage to the bond strength. It was also possible to verify that the surface interaction between MDP and disilicate interferes with the bond strength, but higher concentrations of MDP are necessary for it to be evidenced.

Keywords: Silane. Functional monomer. Universal ceramic primers. Adhesive bonding. Glass ceramics. 